Micro Notes, Marine Micropaleontology

THE NICHE OF BENTHIC FORAMINIFERA, CRITICAL THRESHOLDS AND PROXIES

\author{
John W. Murray
}

School of Ocean and Earth Science, Southampton Oceanography Centre, European Way, Southampton SO14 3ZH, England

Keywords: benthic foraminifera, niche, proxies, organic carbon flux, oxygen

\begin{abstract}
Ecological studies of benthic foraminifera are carried out to explain patterns of distribution and the dynamics of communities. They are also used to provide data to establish proxy relationships with selected factors. According to niche theory, patterns of distribution of benthic foraminifera are controlled by those environmental factors that have reached their critical thresholds. For each species, in variable environments different factors may be limiting distributions both temporally and spatially. For a species or an assemblage to be useful as a proxy its abundance must show a srong correlation with the chosen factor. Since numerous factors influence each species, it is only in those environments where the majority of factors show little variation but one particular factor shows significant variation that proxy relationship for that factor can be determined. On theoretical grounds, the reliability of using foraminiferal abundance as a proxy of a selected environmental factor should be restricted to the range close to the upper and lower thresholds. For oxygen, foraminifera are potential proxies for the lower limits but once oxygen levels rise to values of perhaps $>1$ or $2 \mathrm{ml} \mathrm{l}^{-1}$ there is no longer a relationship between oxygen levels and abundance. By contrast, the flux of organic matter over a large range shows a sufficiently close relationship with foraminiferal assemblages that transfer functions can be derived for the deep sea. However, the relationship at species level is far less clear cut. Much more accurate estimates of primary productivity and modern organic flux rates are required to improve the determination of past flux rates.
\end{abstract}

\title{
Introduction
}

The concept of using organisms as proxies for specific environmental parameters that cannot otherwise be measured is clearly attractive for reconstructing palaeoecology and palaeoceanography in some detail. Benthic foraminifera have the potential to operate as proxies of environmental factors in two ways: chemical and biological. The chemical pathway is when an element is incorporated into a shell in proportion to a parameter and it operates over the whole range of that parameter (e.g., stable isotopes, nutrient proxies $\mathrm{Cd}$ and $\mathrm{Ba}$, physical proxies $\mathrm{Mg}$, Sr, etc., Lea, 1999). Such proxies are not dependent 
on the abundance of the shells; all that is required is enough shells to give analytical precision. By contrast the biological pathway involves covariation between either the abundance of an organism or the composition of an assemblage of organisms and a given environmental parameter.

It is important for the health of science that new ideas are introduced but it is equally important to test them in the light of new evidence. Ecologists seek to explain patterns of distribution and the dynamics of communities of organisms. In the case of organisms that have preservable hard parts, their fossil remains can be used for palaeoecological reconstructions of former environments. Thus, palaeontologists and palaeoceanographers depend on the application of the results from ecological studies for their interpretation of past faunal records. Whereas ecologists consider a range of factors that influence distributions, those interpreting the fossil record often have a more restricted objective.

For benthic foraminifera, in recent years the emphasis has been extended from providing general environmental interpretations to attempting to quantify certain selected parameters (especially dissolved oxygen and the flux of organic carbon) using benthic foraminifera as proxies. The purpose of this note is to draw attention to the need to disentangle these two related but nevertheless separate topics and to consider some basic concepts. Essentially these are that although patterns of distribution are controlled by numerous factors (even though one may be locally more important than the others), proxies depend on there being a well-defined relationship between the abundance of an organism or community and the magnitude of a given environmental factor. Just because a distribution pattern can be explained in relation to one particular environmental factor, it does not automatically follow that the relationship is sufficiently robust to be used as a proxy for that factor. This note is concerned with ideas rather than a review of the entire subject so no attempt has been made to list all the relevant literature.

\section{Patterns of distribution}

The way that environmental factors control the distribution of foraminifera remain poorly understood. Each species has its own unique niche influenced by a large number of abiotic and biotic factors; for survival, the numerical values of all these factors must lie within the upper and lower critical threshold tolerance limits peculiar to that species (Pielou, 1974). Ecologists also recognise that a distinction must be made between the fundamental niche (that is, the ecospace where a species could potentially exist) and the realised niche, where the species really does exist and which is always a smaller part of the ecospace (Fig. 1). The sum of the realised niches of different geographic areas probably occupies a greater part of the fundamental niche than any one of them does individually. Attempts to define niches come from field studies and laboratory experiments. Since there may be a lag between a change in a factor and the response of individuals then it is often difficult to relate field measurements of factors to faunal response. Experimental studies artificially isolate individual factors in order to determine threshold values and commonly show that the critical limits for a given factor are more extreme than those suggested through field studies. Under natural conditions some factors operate together and this may change thresholds. In reality it is extremely difficult to determine the niche although attempts have been made for a few species by Lee (1974). Interestingly, neither food supply nor oxygen were 
parameters that were considered important determinants at that time although both Phleger (1960, p. 189 ) and Murray (1973, p. 230) had pointed to the importance of food.

Although it is convenient to think of the niche operating at the scale of species distributions, in practise it also operates at a smaller scale. For example, niches operate on local patches and even at the scale of the individual, where there may be small but significant differences (around the critical thresholds) in the values of factors associated with patch scale spatial or temporal variability in the environment. Also, foraminifera have the ability to withstand (for some days or even longer) the effects of some factors that have exceeded the expected critical threshold (e.g., anoxia, see review by Bernhard and Sen Gupta, 1999). Indeed, many foraminifera are opportunistic and great survivors; they exist in small numbers for long periods when conditions are far from optimal but when conditions change in their favour they rapidly increase their numbers. The so-called 'phytodetritus species' (Gooday, 1992 ) and Stainforthia fusiformis (Alve, 1994 ) are good examples of this.

The importance of biotic factors should not be neglected although they are often difficult to quantify. For example, through experimental studies the critical thresholds of temperature, salinity, oxygen and sediment grain size were determined for the fundamental niche of the meiofaunal polychaete Protodriloides symbioticus; the realised niche (based on field observations) was just a small part of the fundamental niche. Not all apparently suitable substrates were colonised and it was found that only those containing a particular species of bacterium were attractive (due to a tactile chemical response). Furthermore, P. symbioticus will not colonise sands occupied by the gastrotrich Turbanella hyalina because it produces a chemical that is offensive to the polychaete (Gray, 1981). The distribution of epifaunal foraminiferal taxa such as Cibicides lobatulus and Rosalina globularis is limited by the availability of firm substrates such as hydroids, shells, and rock surfaces that project above the sea bed and they do not live on associated sandy sediment substrates (although their dead tests accumulate there). Thus, in these cases the response to these factors is essentially binary rather than gradational.

At any one time the factor or factors close to the threshold of tolerance for any given species are those that will limit its local distribution. It follows that for each species living in continually varying environments it is probable that different factors or a combination of factors may be limiting distributions both temporally and spatially. This in turn explains why in such areas there is a strong correlation between certain foraminifera and one particular factor while in other areas there is not and also accounts for the lack of a consistent regional pattern of correlation between individual species and any single factor (Murray, 1991).

\section{Organisms as proxies}

In the ideal situation there would be strong correlation between the abundance of a species and the value of an environmental factor but, because biological systems are never that ordered and most environmental parameters vary temporally, this is perhaps a false hope. Even if a species responded to a factor with its abundance following a Gaussian curve and the peak abundance correlated with 
optimum conditions, there would still be the problem that the lowest abundances would occur at both ends of the spectrum (i.e., at low and high values of the factor). In reality, once a factor reaches a level well within the limits of the critical thresholds, there is no reason for faunal abundance to be directly linked to that factor because species respond to a plexus of factors not all of which will be at their optimum.

To overcome the difficulties of dealing with individual living species, some authors use transfer functions based on dead assemblages which give a time-averaged record over many years which is then compared with environmental data based on a much shorter timescale (rarely longer than one year). At present, transfer functions have been developed for benthic foraminifera in relation to their value as indicators of sea level (Horton, et al., 1999) and organic carbon flux (e.g., Loubere, 1991; Kuhnt, et al., 1999; Wollenburg and Kuhnt, in press). Indeed, in a comprehensive review of palaeoecological concepts and proxies, Van der Zwaan, et al. (1999) suggested that the potential use of foraminifera as proxies was very limited, perhaps just to oxygenation and organic flux and that even for distributions apparently related to water depth, oxygen and flux of organic material were the more likely controls.

At present it is fashionable to consider benthic foraminiferal distributions as being controlled largely by oxygen levels and food supply. This may be partly due to the study of those environments where it might be true (e.g., deep water areas where other chemical factors do not show much variation, although there might still be variation in physical attributes such as substrate type and disturbance). However, on the continental shelf and in marginal marine environments, other factors have been shown to play a major role (see review by Murray, 1991) and it would be too simplistic to attempt to define all distributions in terms only of oxygen and food supply. Furthermore, the success of the foraminifera must be attributed to their ability to tolerate a broad range of environmental conditions.

From the above discussion, it can be seen that it is only in environments where there is variability in one principal factor (or at most two) for foraminifera to be potentially effective proxies. This means that their use is likely to be largely restricted to deeper water for oxygen and organic flux and to marshes in the case of sea level.

\section{Oxygen}

In muddy sediments the redox boundary is normally within a few $\mathrm{cm}$ of the sea floor even in those environments where the overlying bottom water is well oxygenated. Thus, all muddy environments potentially have oxygen-limited deeper infaunal taxa even though these may live only a few $\mathrm{mm}$ or $\mathrm{cm}$ away from shallow infaunal and epifaunal taxa that have an ample supply of oxygen. Thus, the dead assemblages in muddy sediments consist of a mixture of these different microenvironments. This must be reflected in the use of the foraminiferal oxygen index proposed by Kaiho (1994). Does it measure an 'average' of the sediment and bottom water oxygen contents? In any palaeoecological interpretation, the presence of an oxygen-limited component of the fauna should not automatically be interpreted as evidence of bottom water dysoxia for the reasons given above. In reality, the only low oxygen 
environments that are of interest from a palaeoceanographic point of view are those where dysoxia or anoxia extend into the lower part of the water column.

Because of the difficulty of measuring dissolved oxygen, records are normally taken only at the time of sampling and there are no weekly/monthly time-series data even for classic areas of oxygen depletion such as the California borderland basins. Very low values of oxygen are potentially limiting to aerobic life. Although at present there are no foraminifera (or macrofauna) known to be confined exclusively to low oxygen environments, it has been determined that some species have very low critical thresholds. Therefore an assemblage of such species may be characteristic of a narrow range of oxygen values. Indeed, such assemblages have been used as proxies in the range from very low $\left(<0.05 \mathrm{ml} \mathrm{l}^{-1}\right)$ up to values of $1.0 \mathrm{ml} \mathrm{l}^{-1}$ in the Santa Barbara Basin, California, USA (Bernhard et al., 1997). Even in this range it should not be automatically assumed that oxygen is always the sole limiting parameter. Nevertheless, when oxygen is undoubtedly sufficiently abundant not to be limiting (probably values $>1$ or $2 \mathrm{ml} \mathrm{l}^{-1}$ ) foraminifera are not proxies for specific values because, as yet, no species is known to have its abundance linked directly to oxygen in this range. Therefore, foraminifera have the potential to serve as proxies for very low values but once oxygen is abundant, they cease to be effective proxies. The same seems to be true for bathyal macrofauna, as Levin and Gage (1998) found that oxygen showed a significant relationship with species diversity for those stations with $<1 \mathrm{ml} \mathrm{l}^{-1} \mathrm{O}_{2}$. They suggested that '.. there is an oxygen threshold (below $1 \mathrm{ml} \mathrm{l}^{-1}$ and probably $<0.45 \mathrm{ml} \mathrm{l}^{-1}$ ) above which oxygen has a relatively minor influence on macrobenthic species richness, but below which it is a powerful control.'

\section{Primary production and the flux of organic matter to the sea floor}

Where primary productivity by phytoplankton is $<200 \mathrm{~g} \mathrm{orgC}^{-2} \mathrm{yr}^{-1}$, there is a positive linear relationship between productivity and export but above this level there is a fall in the export ratio with increase in total production (Lampitt and Antia, 1997).

Export production comprises particulate organic matter (POM) which is consumed or oxidised as it descends through the water column and therefore the deeper the water, the smaller the proportion of POM will reach the sea floor. Empirical equations have been established to determine the amount of loss with respect to depth (e.g., Müller and Suess, 1979; Suess, 1980; Berger, et al. 1988). However, these equations apply only to the continuous rain of POM. Where the input of POM is seasonally pulsed, as with blooms of diatoms and other phytoplankton, the rate of descent of the floccules of phytodetritus, diatom mats, or 'fall dump' (i.e., autumn) is rapid and the rate of decay is less (Kemp, et al., 2000, and references therein). On arrival at the sea floor the organic matter may be partly or wholly consumed by benthos or partly or wholly preserved as total organic carbon (TOC) in the sediment.

Labile organic matter is the most readily consumed by foraminifera and is the essential non-living food source (Loubere and Fariduddin, 1999). Resistant material is slowly broken down by bacteria which may then serve as a food source for benthic foraminifera. Refractory organic matter is inert and not available as a food source. Thus, it can be seen that the relationship between primary production, rate of descent though the water column and decay of POM, and availability of labile POM as a food 
resource on the sea floor is complex. This has profound implications for the use of benthic foraminifera as a proxy for primary production.

Studies of the relationship between organic flux and benthic foraminifera are either (a) to explain patterns of distribution of assemblages or individual taxa, or (b) to use foraminiferal abundance as a proxy for organic production in the surface waters. At present, neither the mechanisms that control the response of foraminifera to the organic flux nor the role of foraminifera in the benthic community are well understood (Loubere and Fariduddin, 1999).

Explaining distributions: The role of organic matter in controlling distributions rather than abundance of shallow water foraminifera is not clear because these environments show great variation in a wide range of factors. However, in the deep sea, some factors show little variation over large areas (e.g., temperature, salinity) so it is easier to determine the role of variations in food supply. For instance, Loubere (1991) studied a transect in the eastern equatorial Pacific where the surface productivity gradient was the only changing environmental variable of those measured. The principal component factor scores derived for time-averaged dead assemblages were regressed on sea surface productivity and showed a strong correlation $\left(\mathrm{r}^{2} 0.87\right)$.

One of the major ecological discoveries of the last decade is that the deep sea is subject to seasonal influences due to the input of phytodetritus. Some species respond rapidly by moving out of the sediment into the newly arrived phytodetritus to feed, reproduce and increase their standing crop (Gooday, 1992; 1996). At other times of the year they live in small numbers in the sediment. While it is clear that the number of individuals is usually controlled by the abundance of food, it is less clear that the latter also controls their distribution because such species also occur in areas not known to have pulsed inputs of food (e.g., eastern Pacific, Loubere, 1998).

Proxies: The key question is whether the abundance of either individual taxa or of particular assemblages shows a strong correlation with the flux of organic carbon. Only if such relationships exist can foraminifera be used as a proxy for organic flux. This implies that no other environmental factor is sufficiently variable to be a significant influence. A problem is that in most benthic foraminiferal studies the flux of organic matter is invariably estimated and therefore there is a large degree of uncertainty about the true flux of organic material to the sea floor.

The most comprehensive anaylsis of the relationship between organic flux and benthic foraminiferal abundance is that of Altenbach, et al. (1999) using data from the equatorial Atlantic to the Arctic Ocean. It is an implicit assumption in this study that the different bottom water mass characteristics had no significant influence on the faunas and the discussion of organic flux is in isolation from all other factors. The flux values over which an individual species exists range from one to three orders of magnitude and the range is greatest at the lowest foraminiferal abundances. From this, the authors concluded: 'Due to this broad adaptability of benthic foraminifera to different flux regimes in general, 
the presence or absence of a single species or a calculated mean flux value for a species does not seem a valuable measure for the reconstruction of flux rates' (ibid., p. 175). However, the higher abundances of individual taxa show a much smaller range which the authors considered to be the "environmental optimum'. Nevertheless, Van der Zwaan, et al. (1999, p. 222) consider that '. . peak abundances of species are not consistently related to flux alone.'

At depths of less than $1000 \mathrm{~m}$ organic fluxes have reduced ecological influence and Altenbach, et al. (1999) consider that species distributions are more depth related. On continental shelves, estimates of vertical flux rates may be meaningless due to resuspension and lateral advection of material. At depths $>1000 \mathrm{~m}$ flux rates of $2-3 \mathrm{~g}$ orgC $\mathrm{m}^{-2} \mathrm{yr}^{-1}$ represent a critical threshold with values $>3 \mathrm{~g}$ restricted to areas of high primary productivity. Nevertheless, it was concluded that ' . . o only $4 \%$ to $64 \%$ of the distribution patterns found are derived from flux rates.' (ibid, p. 183). They consider that use of assemblages holds greatest promise for reconstructing past flux rates.

Studies which make use of multivariate factor-defined assemblages of foraminifera and organic flux find a good correlation between the two (Loubere, 1991: eastern equatorial Pacific; Kuhnt, et al., 1999: South China Sea; Wollenburg and Kuhnt, in press: Arctic Ocean). These studies demonstrate that each geographic area requires its own calibrated data set in order to determine the best transfer function. As Loubere and Fariduddin (1999) point out, 'Confident assessments of paleoproductivity will require a better understanding of which portion of the organic carbon signal different benthic foraminifera respond to' (ibid., p. 199).

Although an increase in food supply might seem to be advantageous for the fauna, this is not always the case. For the macrofauna it has been suggested that species diversity shows a parabolic pattern with low values at both low and high abundance of food (Pearson and Rosenberg, 1978). This also seems to apply to those foraminiferal assemblages associated with phytodetritus (Gooday, 1996) which lie on the high organic matter - low species diversity side of the parabola. Wollenburg, et al. (in press) consider that in the Arctic Ocean there is a positive coerrelation between species diversity and organic carbon flux only where the latter is $<7 \mathrm{~g} \mathrm{orgC} \mathrm{m}^{-2} \mathrm{yr}^{-1}$. Others have argued that for the macrofauna '. food availability .. exerts primary control on dominance and evenness' rather than species diversity (Levin and Gage, 1998).

In reality, quantitative estimates of palaeofluxes of organic matter should still be treated with caution until much more is known about modern export production and foraminiferal response. Nevertheless, conclusions about organic flux rates can be drawn in a non-quantitative way. For instance, the correlation between pulsed inputs of phytodetritus to the deep-sea floor and the increase of opportunistic species such as Epistominella exigua is well established. In the fossil record, the relative abundance of this species can be used as an indicator of pulsed phytodetritus (Smart, et al., 1994) but it is not yet possible to quantify the amount, duration or frequency of input. It has been argued by Schnitker (1994) that in the deep-sea benthic foraminifera are good indicators of productivity where 
productivity is high, but in areas of low productivity the foraminiferal distributions are more clearly related to the distribution of bottom water masses. This remains to be tested. The study by Altenbach, et al. (1999) is a major step forward and shows that there is considerable potential for further progress when more accurate estimates of organic flux become available.

\section{Summary}

Explaining patterns of distribution requires consideration of a broad range of environmental factors. If the niche concept is valid, then it should not be expected that all distributions can be explained in terms of just a few factors, such as oxygen and flux of organic matter, as this would be too simplistic. Indeed, local distributions will be explained by a range of different factors (reaching critical thresholds singly or in combination) at different times and in different places. However, in deeper waters where several environmental factors show little or no spatial or temporal variability it is sometimes possible to isolate one main factor as the principal control. In this situation the main ones appear to be oxygen and flux of organic carbon.

More thought needs to be given to the conceptual basis of using biological proxies based on species abundance. It may be possible to reconstruct fairly precise values for a factor such as oxygen but only at the lower critical range since above this, at the present state of knowledge, there is no known correlation between oxygen and abundance. Also, it must be remembered that virtually all muddy substrates are anoxic within a few $\mathrm{cm}$ of the sediment surface even where the overlying bottom waters are amply oxygenated; therefore the presence of some low-oxygen taxa does not necessarily indicate bottom water anoxia. At present some authors believe that assemblages rather than individual taxa of foraminifera are more reliable guides to organic flux but each area requires its own calibration data set to determine the transfer function. Other authors consider that associations of species are less dependent on flux (Van der Zwaan, et al., 1999). There is still a great deal of uncertainty about the estimates of primary production and the downward flux of organic carbon. When these are improved there is real potential to use benthic foraminifera to give more reliable estimates of organic flux in the deep ocean.

\section{Acknowledgements}

I am grateful to Richard Lampitt, Patrick Holligan and Alan Kemp (Southampton Oceanography Centre, UK) for discussions on primary productivity and export production and to Lisa Levin (California, USA) for discussions on oxygen. This manuscript benefitted greatly from thoughtful comments from Alexander Altenbach (Munich, Germany), Elisabeth Alve (Oslo, Norway), Joan Bernhard (South Carolina, U.S.A.), Ahuva Almogi-Labin (Israel), the reviewers Jan Willem Zachariasse (Germany) and Wolfgang Kuhnt (Kiel, Germany) and the editor, Dave Lazarus (Berlin, Germany). I thank them all for their help and encouragement.

\section{References}

Altenbach, A.V., Pflaumann, U., Schiebel, R., Thies, A., Timm, S., Trauth, M., 
1999. Scaling percentages and distributional patterns of benthic foraminifers with flux rates of organic carbon. Journal of Foraminiferal Research, 29, 173185.

Alve, E., 1994. Opportunistic features of the foraminifer Stainforthia fusiformis (Williamson): evidence from Frierfjord, Norway. Journal of Micropalaeontology, 13, 24.

Berger, W.H., Fischer, K., Lai, C., and Wu., G., 1988. Ocean carbon flux: global maps of primary production and export production. In: Agegian, C.R. (ed.) Biogeochemical cycling and fluxes between the deep euphotic zone and other oceanic realms. NOAA National Undersea Research Program, Research Reports, 88, (1), 131-176.

Bernhard, J.M., and Sen Gupta, B.K., 1999. Foraminifera of oxygen-depleted environments. In: Sen Gupta, B.K., (ed.). Modern foraminifera. Kluwer, Dordrecht. pp. 201-216.

Bernhard, J.M., Sen Gupta, B.K., and Borne, P.F., 1997. Benthic foraminiferal proxy to estimate dysoxic bottom-water oxygen concentrations: Santa Barbara Basin, U.S. Pacific continental margin. Journal of Foraminiferal Research, 27, 301-310.

Gooday, A.J., 1992. The role of benthic foraminifera in deep-sea food webs and carbon cycling. In: Rowe, G.T., and Pariente, V., (eds), Deep-sea food chains and the global carbon cycle, 63-91.

Gooday, A.J., 1996. Epifaunal and shallow infaunal foraminiferal communities at three abyssal NE Atlantic sites subject to differeing phytodetritus input regimes. Deep-Sea Research, I 43, 1395-1421.

Gray, J.S., 1981. The ecology of marine sediments. Cambridge studies in modern biology 2. Cambridge University Press, Cambridge.185 pp.

Horton, B.P., Edwards, R.J., and Lloyd, J.M., 1999. A foraminiferal-based transfer function for sea-level studies. Journal of Foraminiferal Research, 29, 117-129.

Kaiho, K., 1994. Benthic foraminiferal dissolved-oxygen index and dissolved-oxygen levels in the modern ocean. Geology, 22, 719-722.

Kemp, A.E.S., Pike, J., Pearce, R.B., and Lange, C.B., 2000. The "fall dump" - a new perspective on the role of the "shade flora" in the annual cycle of diatom production and export flux. Deep-Sea Research, II 47, 2129-2154.

Kuhnt, W., Hess, S., and Jian, Z., 1999. Quantitative composition of benthic foraminiferal assemblages as a proxy indicator for organic carbon flux rates in the South China Sea. Marine Geology, 156, 123-157.

Lampitt, R. S., and Antia, A.N., 1997. Particle flux in deep seas: regional characteristics and temporal variability. Deep-Sea Research 1, 44, 1377-1403.

Lea, D.W., 1999. Trace elements in foraminiferal calcite. In: Sen Gupta, B.K., (ed.). Modern foraminifera. Kluwer, Dordrecht. pp. 250-277. 
Lee, J. J., 1974. Towards understanding the niche of foraminifera. In: Hedley, R.H., and Adams, C.G. (eds), Foraminifera, 1, 207-260.

Levin, L.A., and Gage, J., 1998. Relationship between oxygen, organic matter and diversity of bathyal macrofauna. Deep-Sea Research, II 45, 129-163.

Loubere, P., 1991. Deep-sea benthic foraminiferal assemblage response to a surface ocean productivity gradient: a test. Paleoceanography, 6, 193-204.

Loubere, P., 1998. The impact of seasonality on the benthos as reflected in the assemblages of deep sea foraminifera. Deep-Sea Research 1, 45, 409-432.

Loubere, P., and Fariduddin, M., 1999. Benthic foraminifera and the flux of organic carbon to the seabed. In: Sen Gupta, B.K., (ed.). Modern foraminifera. Kluwer, Dordrecht. pp. 181-199.

Müller, P.J., and Suess, E., 1979. Productivity, sedimentation rate, and sedimentary organic matter in the oceans - I. Organic carbon preservation. Deep-Sea Research, 26A, 1347-1362.

Murray, J.W., 1973. Distribution and ecology of benthic foraminiferids. Heinemann Educational Books, London. 274 pp.

Murray, J.W., 1991. Ecology and palaeoecology of benthic foraminifera. Longman, Harlow, 397 pp.

Pearson, T. H., and Rosenberg, R., 1978. Macrobenthic succession in relation to organic enrichment and pollution of the marine environment. Oceanography and Marine Biology Annual Review, 16, 229-311.

Phleger, F.B., 1960. Ecology and distribution of recent foraminifera. The Johns Hopkins Press, Baltimore. 297 pp.

Pielou, E.C., 1974. Population and community ecology: principles and methods. Gordon and Breach, New York, 424 pp.

Schnitker, D., 1994. Deep-sea benthic foraminifera: food and bottom water masses. In: Zahn, R., et al., (Eds), Carbon cycling in the global ocean: contraints on the ocean's role in global change. Springer Verlag, NATO ASI Series, I17, 539554 .

Smart, C.W., King, S.C., Gooday, A.J., Murray, J.W., Thomas, E., 1994. A benthic foraminiferal proxy of pulsed organic matter paleofluxes. Marine Micropaleontology, 23, 89-99.

Suess, E., 1980. Particulate organic carbon flux in the oceans - surface productivity and oxygen utilization. Nature, 288, 260-263.

Van der Zwaan, G.J., Duijnstee, I.A.P., Dulk, M. den, Ernst, S.R., Jannink, N.T., Kouwenhoven, T.J., 1999. Benthic foraminifers: proxies or problems? A review of paleoecological concepts. Earth-Science Reviews, 46, 213-136.

Wollenburg, J.E., and Kuhnt, W., in press. The response of benthic foraminifers to 
carbon flux and primary production in the Arctic Ocean. Marine

Micropaleontology,

Fig. 1. The fundamental niche (large oval) encloses the smaller realised niche (dark circle). The niche is multidimensional but for simplicity only two are shown here. Adapted from Gray (1981).

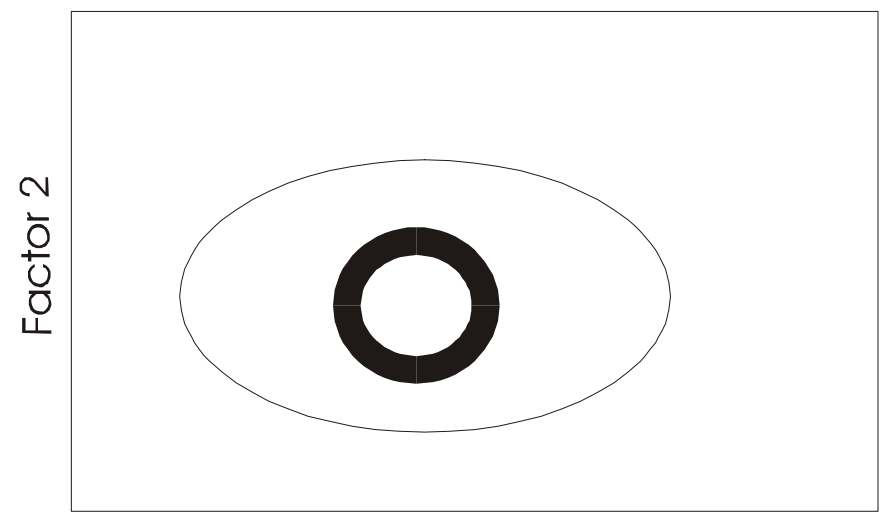

Factor 1 
